\title{
The Challenges of Using the Differentiated Instruction Strategy: A Case Study in the General Education Stages in Saudi Arabia
}

\author{
Ali Tared Aldossari ${ }^{1}$ \\ ${ }^{1}$ Department of Curriculum \& Instruction, College of Education, Imam Abdulrahman Bin Faisal University, \\ Kingdom of Saudi Arabia \\ Correspondence: Ali Tared Aldossari, Department of Curriculum \& Instruction, College of Education, Imam \\ Abdulrahman Bin Faisal University, Kingdom of Saudi Arabia. E-mail: ataldossari@iau.edu.sa
}

Received: January 22, 2018

Accepted: February 25, $2018 \quad$ Online Published: March 28, 2018

doi:10.5539/ies.v11n4p74

URL: https://doi.org/10.5539/ies.v11n4p74

\begin{abstract}
The study identifies the most important challenges facing general education male and female teachers in applying the differentiated instruction strategy in different stages of education in the Eastern Province in the Kingdom of Saudi Arabia. To achieve this, the researcher designed a questionnaire consisting of 47 paragraphs on five axes. It was distributed to 275 male and female teachers in Dammam city, after having verified its validity and stability,

The results indicate that the degree of the challenge of using the differentiated instruction strategy was medium overall. The challenges related to students were ranked first, followed by challenges related to the school environment, then the nature of the differentiated instruction, challenges related to teachers, and, finally, challenges related to study courses.

However, the results were not statistically significant for the variable of the educational stage (primary, intermediate, and secondary), although there were significant differences for the gender variable in favour of males.

The study recommends creating a school environment that supports the use of a differentiated instruction strategy and holding workshops for teachers to train them in differentiated instruction activities.
\end{abstract}

Keywords: differentiated instruction, challenges (obstacles), male and female teachers

\section{Introduction and Theoretical Framework}

The emphasis on quality over quantity in teaching is a result of the accumulation of expertise in various areas of knowledge. The accumulation of knowledge is assisted in the modern era by technological development. However, many challenges still face the education system because of the wide spectrum of students' differences, needs and concerns, and patterns of thinking. These differences require teachers to respond using a variety of approaches.

The teacher's acquisition of basic teaching skills drives the process of education for the better, and enhances the achievement of the goals set for the education process. In order to achieve the wider objectives of building and developing societies through education, learners' behaviours have to be changed, especially in line with developments in research related to the brain, multiple intelligences and structural theory.

Against this background, the concept of differentiated instruction has emerged, and received considerable attention within education systems. The focus has been boosted at relevant conferences, such as the World Conference on Education held in Jomtien (1990), and educational conferences in the Kingdom of Bahrain (2010) and in the State of Kuwait (2010), as well as by researchers, such as Al Raee (2014), Ahalise (2011), and Al Magrabe (2011), in the field of education and psychology.

Educationalists have applied many terms to this type of instruction; it was termed "differentiated instruction" by Obeedat and Abu-Al Semaid (2009), while Tkogko et al. (2008) referred to it as "varied instruction", Attia called it "differentiated teaching" (2009), and Al-Laqani and Gamal (2003) named it "contrast instruction". However, all the terms refer to one concept, which concerns the multi-level differences among learners.

Thus, Ziebell (2002) defines differentiated instruction as a way of teaching in which the teacher provides multiple entries that meet the needs of each learner in the classroom, in order to maximize the students' potentialities. Similarly, Obeedat and Abu-Al Semaid (2009) define differentiated instruction as a way of teaching that aims to 
raise the level of all students, not just the students who have problems with achievement. It is a policy that takes into account the characteristics of the individual and his/her previous experience and aims to increase their abilities by providing an educational environment suitable for all students. Meanwhile, Campbell (2008) views differentiated instruction as a series of measures to teach students with differing abilities in a single classroom. A student-centred approach addresses their needs and is based on clear practices to improve the students' achievements. Along the same lines, Koeze (2007) sees differentiated instruction as a set of the best practices in teaching, teaching theories, and practices that support the students' achievements, while Bantis (2008) defines it as a teaching method, which varies depending on the teaching needs of students in multi-level and multi-abilities classrooms. Equally, Attia (2009) defines differentiated instruction as an educational system that aims at achieving one learning output through different educational procedures based on a multi-intelligence teaching strategy. Also, Shukairat (2009) describes differentiated instruction as an instruction that takes into account the abilities and experiences of all categories of learners in the classroom, and works to increase their achievement and develop their abilities with an acceptable degree of performance, through dealing with each level in a manner appropriate to their abilities and previous experiences. Finally, Kojek et al. (2008) define differentiated instruction as knowing the different needs, tendencies, patterns of learning, preferences, prior knowledge, learning readiness and linguistic level of students, and responding to these in the teaching process.

Based on these definitions, the researcher argues that differentiated instruction is a comprehensive approach for learning and instruction. It stems from the assumption that teaching strategies need to be diversified and adapted to suit the diversity of students' needs in the classroom. Furthermore, this diversity in teaching methods requires knowledge of the students' needs and their preferred learning patterns. Accordingly, differentiated instruction is not just a compilation of a set of teaching strategies, but is an excellent guide to learner-centred learning based on content adaptation (what is taught), processes (how it is taught), and outputs (evaluation and instruction), with a view to promoting integrated learner growth. The best method to fulfil the different needs of learners is to provide the content of the curriculum in a variety of ways, as diversity is the best method through which learners acquire the information, skills and concepts to be learned. Importantly, differentiated instruction requires the positive participation of students in the planning process, implementation, evaluation and decision making (Kojak et al., 2008).

Ellis et al. (2007), Good (2006), Hobson (2008), and Tolison (2008) suggest that differentiated instruction is based on several assumptions and principles that can be summed up as follows:

- The students differ in their experience, knowledge, characteristics, abilities, and degree of response to education.

- Achieving the level of learning required varies from one student to another; this requires different teaching methods that are suitable for each student.

- An expert teacher can identify and appreciate individual differences among students and provide the necessary learning environment for all students in a way that contributes to achieving the desired objectives.

- Instruction and evaluation are two interrelated processes.

- The process of instruction is participatory between the teacher and students.

- Hence, the teacher's possession of the basic skills of teaching improves the process of instruction and enhances the achievement of the objectives set for the process.

- To achieve the objectives of education in building and developing societies, the desired changes in the behaviour of the learner are required. This is achieved by a teacher who disseminates learning material and activities in way which positively encourages learners' interests and attitudes.

\section{The Research Problem}

This study identifies the most important challenges that constrain the use of the differentiated instruction strategy, according to the views of general education male and female teachers (primary, intermediate, secondary) in the Eastern Province of the Kingdom of Saudi Arabia. The research is in response to the wave of modernization in the education system in general, and the adoption of modern teaching strategies in particular.

The research problem is identified through the following questions:

1) What are the main challenges of using differentiated instruction strategy, which are related to the school environment?

2) What are the main challenges of using differentiated instruction strategy, which are related to male and female teachers? 
3) What are the main challenges of using differentiated instruction strategy, which are related to the students?

4) What are the main challenges of using differentiated instruction strategy, which are related to school courses?

5) What are the main challenges of using differentiated instruction strategy, which are related to the nature of the strategy itself?

6) Are there any statistically significant differences in the challenges of using a differentiated instruction strategy according to the educational stage?

7) Are there any statistically significant differences in the challenges of using a gender-specific education strategy?

\section{Study Objectives}

1) Identify the most important challenges that prevents the effective use of the differentiated instruction strategy in the classroom environment.

2) Examine the significance of the differences between the mean response rates of the male and female teachers to the challenges of using the differentiated instruction strategy, according to the variables of the educational stage and gender.

\section{Importance of the Study}

The importance of this study arises from the following considerations:

1) It tackles the subject of differentiated instruction strategy, which is a subject of interest to psychologists and educationalists.

2) It is consistent with the objectives of the general education in the Kingdom of Saudi Arabia, its vision that is focused on students, who are at the centre of the learning and teaching process, and teaching through modern strategies that a wide range of studies have proved effective.

3) The results of this study can help guide general education departments in the Kingdom of Saudi Arabia towards the development of classroom environments that use modern teaching strategies.

4) This study provides a measure of the challenges that curtail the application of the differentiated instruction strategy in the classroom, according to the view of the teachers of general education in the Eastern Province.

\section{Limitations of the Study}

1) Time limits: The research took place in the second semester of the Saudi academic year (2015/2016).

2) Locality limits: The research took place in general education schools in the city of Dammam in the Eastern Province of the Kingdom of Saudi Arabia.

3) Human limits: The research sample was male and female teachers in the general education stages in the city of Dammam in the Eastern Province of the Kingdom of Saudi Arabia.

4) Objective limits: The Challenge Questionnaire consists of 47 paragraphs divided into five challenges related to the school environment, the teachers, the nature of the differentiated instruction strategy, the students, and the school courses.

\section{Operational Definitions}

Differentiated instruction: This means to identify the needs, tendencies, patterns of learning, preferences, prior knowledge, learning readiness and linguistic level of learners, and then to respond to these elements in the teaching process (Kojak et al., 2008).

The challenges of using a differentiated instruction strategy: These are the factors or conditions that prevent the efficient and effective use of the differentiated instruction strategy in the classroom environment. This was determined operationally by the research questionnaire.

\section{Methodology}

\subsection{Study Method}

The study uses an analytical descriptive method, which is based on studying the phenomenon, quantifying it digitally, and justifying the results.

\subsection{Study Society}

The study society consists of the 27,794 male and female teachers employed in the second semester of 2015/2016 in Dammam, Eastern Province, Kingdom of Saudi Arabia. 


\subsection{Study Sample}

The study Instrument was applied to a sample of 275 male and female teachers in different general education stages in Dammam according to the variables shown in Table 1.

Table 1. Distribution of sample by the study variables

\begin{tabular}{cccc}
\hline \multirow{2}{*}{ Education Stage } & \multicolumn{2}{c}{ Gender } & \multirow{2}{*}{ Total } \\
\cline { 2 - 3 } & Male & Female & \\
\hline Primary & 14 & 79 & 93 \\
Intermediate & 32 & 49 & 81 \\
Secondary & 80 & 21 & 101 \\
Total & 126 & 149 & 275 \\
\hline
\end{tabular}

\subsection{Study Instruments}

A measure of the challenges of using the differentiated instruction strategy is achieved through the use of a questionnaire prepared by the researcher. In its initial form it had 51 paragraphs, divided into five axes. Each question had a five-fold response scale, according to the Likert scale - a very large degree, a large degree, a medium degree, a small degree, and a very small degree. The scores were given marks ranging from 1 to 5 , according to the response. In order to judge the degree of the challenges, the averages were given the following scale:

$1.00-2.33=$ low, $2.34-3.67=$ medium, and higher than $3.67=$ high.

The questionnaire paragraphs were distributed randomly before applying them to the targeted sample.

\subsubsection{Validity of the Study Instrument}

The method of logical honesty was used in order to verify the validity of the questionnaire. The questionnaire sections were presented to a group of experienced and competent arbitrators in order to determine their opinion on the validity and clarity of the paragraphs in relation to the educational and linguistic aspects of the research and to suggest any amendments to the questionnaire. If the paragraphs obtained an agreement percentage of $80 \%$ and above, they were accepted. In light of the feedback, the researcher made a number of amendments proposed by the arbitrators, which included the exclusion of four paragraphs, and amending the language of certain paragraphs. Finally, the final document consisted of 47 paragraphs across five axes.

\subsubsection{Reliability of the Study Instrument}

To ascertain the stability of the study scale, the internal consistency method was used by applying the scale to a survey sample from outside the study. This consisted of 21 teachers. The stability coefficients were derived using the Cronbach Alpha equation. The coefficient stability scale of the total mark was 0.89 , which is an acceptable value for the purposes of this study.

\section{Study Results and Analysis}

The first study question was: "What are the main challenges of using a differentiated instruction strategy related to the school environment?". To assess the answers the arithmetical averages, standard deviations and the relative weight of the responses of the study sample members were extracted from the responses of the study sample. These are shown in Table 2. 
Table 2. Challenges related to the school environment

\begin{tabular}{|c|c|c|c|c|}
\hline Serial & Statement & Average & $\begin{array}{l}\text { Standard } \\
\text { Deviation }\end{array}$ & Order \\
\hline 1 & Classrooms are not suitable for the implementation of a differentiated instruction strategy. & 3.88 & 1.023 & 4 \\
\hline 2 & The overload of administrative responsibilities assigned to the teacher. & 3.96 & 1.001 & 3 \\
\hline 3 & $\begin{array}{l}\text { Lack of availability of educational equipment and Instruments to apply the differentiated } \\
\text { instruction strategy. }\end{array}$ & 4.05 & 0.865 & 2 \\
\hline 4 & Density of students per classroom. & 4.52 & 0.756 & 1 \\
\hline 5 & $\begin{array}{l}\text { Lack of interest by the school administration in the need to use a differentiated instruction } \\
\text { strategy. }\end{array}$ & 2.53 & 1.101 & 8 \\
\hline 6 & The school administration does not encourage teachers to apply modern teaching methods. & 3.80 & 1.181 & 5 \\
\hline 7 & The continuous assessment system does not fit the use of a differentiated instruction strategy. & 3.31 & 1.132 & 6 \\
\hline 8 & $\begin{array}{l}\text { The lack of interest of the educational supervisor and his follow-up to the use of the } \\
\text { differentiated instruction strategy in teaching. }\end{array}$ & 2.70 & 1.029 & 7 \\
\hline \multicolumn{2}{|c|}{ Average of the axis } & 3.59 & 1.113 & \\
\hline
\end{tabular}

It is clear from the data Table 2 that according to the respondents the biggest challenges facing male and female teachers in the use of differentiated instruction strategies related to the school environment, "The density of students per classroom". The arithmetic mean is 4.52 . The next biggest challenge as seen by the participants is paragraph 3 "The lack of availability of educational equipment and Instruments to apply the differentiated instruction strategy", which has an arithmetic mean of 4.05. The challenge highlighted in paragraph 5 "The lack of interest of the school administration of the need to use a differentiated instruction strategy" came in last with an arithmetic mean of 2.53 .

To answer the second question of the study, "What are the main challenges of using a differentiated instruction strategy related to male and female teachers?", the statistical averages, standard deviations and relative weight of the responses of the study sample members were extracted for the paragraphs of this axis (see Table 3 ).

Table 3. Challenges related to male and female teachers

\begin{tabular}{|c|c|c|c|c|}
\hline Serial & Statement & Average & $\begin{array}{l}\text { Standard } \\
\text { Deviation }\end{array}$ & Order \\
\hline 1 & $\begin{array}{l}\text { Failure to prepare the teacher before service in a way that suits the requirements of } \\
\text { differentiated instruction. }\end{array}$ & 4.11 & 1.901 & 1 \\
\hline 2 & The teacher is used to using traditional teaching methods. & 3.44 & 1.056 & 5 \\
\hline 3 & The teacher's belief that differentiated instruction is an absurdity leading to chaos. & 3.05 & 1.072 & 8 \\
\hline 4 & This type of instruction requires time and effort for preparation. & 3.03 & 1.061 & 9 \\
\hline 5 & The employment of teachers who are educationally unqualified for the teaching profession. & 3.02 & 1.118 & 10 \\
\hline 6 & The weakness of in-service training programs in developing teachers' competencies. & 3.69 & 1.181 & 3 \\
\hline 7 & $\begin{array}{l}\text { Poor teachers' knowledge and awareness of the differentiated instruction strategy and its } \\
\text { activities. }\end{array}$ & 3.51 & 1.175 & 4 \\
\hline 8 & The teacher is not convinced of the importance of using modern teaching strategies. & 3.21 & 1.25 & 6 \\
\hline 9 & $\begin{array}{l}\text { The teacher believes that calmness and discipline inside the classroom can only be achieved } \\
\text { through traditional teaching methods. }\end{array}$ & 3.94 & 0.995 & 2 \\
\hline 10 & The teacher's lack of experience in using the differentiated instruction strategy. & 2.96 & 1.110 & 11 \\
\hline 11 & $\begin{array}{l}\text { The teacher fears that the school administration will not accept the use of a differentiated } \\
\text { instruction strategy with the students. }\end{array}$ & 2.35 & 0.956 & 12 \\
\hline 12 & Not motivating a teacher who uses differentiated instruction strategies. & 3.14 & 1.278 & 7 \\
\hline \multicolumn{2}{|c|}{ Average of the axis } & 3.28 & 1.174 & \\
\hline
\end{tabular}

It is clear from the data in Table 3 that according to the respondents the main challenge of using differentiated instruction strategies related to teachers is paragraph 1 which stated: "Failure to prepare the teacher before service in a way that suits the requirements of differentiated instruction". This has an arithmetic mean of 4.11. Paragraph 9 "The teacher believes that calmness and discipline inside the classroom can only be achieved through traditional teaching methods" came second with an arithmetic mean of 3.94, while the least challenging paragraph was 11, "The teacher fears that the school administration will not accept the use of a differentiated instruction strategy with 
the students" with an arithmetic mean of 2.35 .

To answer the third question of the study, "What are the main challenges of using a differentiated instruction strategy related to students?" the statistical averages, standard deviations and relative weight of the responses of the study sample members were extracted for the paragraphs of this axis, as shown in Table 4 .

Table 4. Challenges related to students

\begin{tabular}{|c|c|c|c|c|}
\hline Serial & Statement & Average & $\begin{array}{l}\text { Standard } \\
\text { Deviation }\end{array}$ & Order \\
\hline 1 & Students' weak motivation for learning. & 3.56 & 0.995 & 7 \\
\hline 2 & The poor achievement of some students makes them prefer traditional methods. & 3.57 & 1.072 & 6 \\
\hline 3 & $\begin{array}{l}\text { Students find difficulty in adapting to the skills and activities of a differentiated instruction } \\
\text { strategy. }\end{array}$ & 2.95 & 0.986 & 8 \\
\hline 4 & Students are used to traditional teaching strategies. & 4.01 & 0.962 & 2 \\
\hline 5 & The differentiated instruction strategy is not suitable for slow learners. & 3.38 & 1.026 & 4 \\
\hline 6 & Weakness of students' conviction in using the differentiated instruction strategy. & 4.03 & 1.171 & 1 \\
\hline 7 & Disparity in individual differences among students. & 3.81 & 1.049 & 3 \\
\hline 8 & Students lack the culture of dialogue and discussion. & 3.70 & 1.017 & 5 \\
\hline \multicolumn{2}{|c|}{ Average of axis } & 3.62 & 0.971 & \\
\hline
\end{tabular}

It is clear from the data shown in Table 4 that according to the respondents the greatest challenges of using of the differentiated instruction strategy related to students is paragraph 6 "Weakness of students' conviction in using the differentiated instruction strategy", which has an arithmetic mean of 4.03. In second place is paragraph 4 "Students are used to traditional teaching strategies" with an arithmetic mean of 4.01. In last place is paragraph 3 "Students find difficulty in adapting with the skills and activities of a differentiated instruction strategy" with an arithmetic mean of 2.95 .

To answer the fourth question of the study, "What are the main challenges of using a different differentiated instruction strategy related to school courses?" the arithmetic averages, standard deviations and relative weight of the responses of the study sample members were extracted for the paragraphs of this axis, as shown in Table 5 .

Table 5. Challenges related to school courses

\begin{tabular}{|c|c|c|c|c|}
\hline Serial & Statement & Average & $\begin{array}{l}\text { Standard } \\
\text { Deviation }\end{array}$ & Order \\
\hline 1 & $\begin{array}{l}\text { The Teacher's Guide does not include explanations of how to use a differentiated instruction } \\
\text { strategy. }\end{array}$ & 3.74 & 1.084 & 1 \\
\hline 2 & There are no model lessons for a differentiated instruction strategy. & 3.71 & 1.021 & 2 \\
\hline 3 & $\begin{array}{l}\text { The inadequacy of the differentiated instruction strategy for achieving the teaching } \\
\text { objectives of some courses. }\end{array}$ & 3.51 & 1.015 & 3 \\
\hline 4 & $\begin{array}{l}\text { The nature of the course content is difficult to teach using a differentiated instruction } \\
\text { strategy. }\end{array}$ & 3.44 & 1.110 & 5 \\
\hline 5 & The design of school courses do not match or cope with a differentiated instruction strategy. & 3.19 & 1.054 & 2 \\
\hline 6 & $\begin{array}{l}\text { The objectives of the courses do not consider developing students' research and thinking } \\
\text { skills. }\end{array}$ & 2.79 & 1.200 & 7 \\
\hline 7 & $\begin{array}{l}\text { The difficulty of transforming the school course according to the differentiated instruction } \\
\text { strategy. }\end{array}$ & 2.51 & 1.18 & 9 \\
\hline 8 & $\begin{array}{l}\text { The lack of course topics to present elements of thrill and excitement that promote } \\
\text { differentiated instruction. }\end{array}$ & 3.48 & 0.937 & 4 \\
\hline 9 & Concentration of courses on cognitive aspects, prompting and memorization. & 2.49 & 1.069 & 10 \\
\hline 10 & The difficulty of linking school courses to the practical life of students. & 2.76 & 1.146 & 8 \\
\hline \multicolumn{2}{|c|}{ Average of axis } & 3.16 & 1.191 & \\
\hline
\end{tabular}

Table 5 shows that according to the respondents the most important challenge related to the school courses is paragraph 1 "The Teacher's Guide does not include explanations of how to use a differentiated instruction strategy", which has an arithmetic mean of 3.74. This is followed by paragraph 2 "There are no model lessons for 
a differentiated instruction strategy" with arithmetic mean of 3.71. The least challenging aspect in this axis according to the respondents is paragraph 9 "Concentration of courses on cognitive aspects, prompting and memorization" which has an arithmetic mean of 2.49 .

To answer the fifth question of the study, "What are the main challenges of using a differentiated instruction strategy that are related to the nature of the strategy itself?" the statistical averages, standard deviations and the relative weight of the responses of the study sample members were extracted for the paragraphs of this axis, as shown in Table 6.

Table 6 . Challenges related to the nature of the differentiated instruction strategy

\begin{tabular}{|c|c|c|c|c|}
\hline Serial & Statement & Average & $\begin{array}{l}\text { Standard } \\
\text { Deviation }\end{array}$ & Order \\
\hline 1 & The teacher avoids using the differentiated instruction strategy because it takes a long time. & 3.69 & 1.085 & 3 \\
\hline 2 & Teachers' lack of knowledge of the differentiated instruction strategy. & 3.60 & 1.1040 & 4 \\
\hline 3 & The use of a differentiated instruction strategy hampers the annual planning of the course. & 3.42 & 1.154 & 7 \\
\hline 4 & The teacher avoids using a differentiated instruction strategy, as it requires great effort. & 3.37 & 1.115 & 9 \\
\hline 5 & The high material cost of training and implementing this type of instruction. & 3.39 & 1.103 & 8 \\
\hline 6 & $\begin{array}{l}\text { The range and diversity of classroom activities associated with the differentiated instruction } \\
\text { strategy. }\end{array}$ & 3.52 & 0.921 & 5 \\
\hline 7 & $\begin{array}{l}\text { What this type of strategy requires students is to be familiar with the skills of scientific } \\
\text { research. }\end{array}$ & 3.76 & 0.828 & 2 \\
\hline 8 & $\begin{array}{l}\text { The need to train male and female teachers intensively to use the differentiated instruction } \\
\text { strategy. }\end{array}$ & 3.84 & 0.955 & 1 \\
\hline 9 & $\begin{array}{l}\text { Flexibility is a distinct characteristic of differentiated instruction classes, and it is difficult to } \\
\text { practice in traditional classes. }\end{array}$ & 3.47 & 0.971 & 6 \\
\hline \multicolumn{2}{|c|}{ Average of axis } & 3.56 & 1.012 & \\
\hline
\end{tabular}

It is clear from the data in Table 6 that according to the respondents the greatest challenge related to the nature of the strategy is paragraph 8 "The need to train male and female teachers intensively to use the differentiated instruction strategy" with an arithmetic mean of 3.84. This is followed by paragraph 7 "What this type of strategies requires from students is to be familiar with the skills of scientific research" with an arithmetic mean of 3.76. The least challenging aspect in this axis according to the respondents is paragraph 4 "The teacher avoids using a differentiated instruction strategy as it requires great effort" with an arithmetic mean of 3.37 .

In order to determine the order of the axes, and to compare these axes, the arithmetic mean and the standard deviation of each axis were extracted separately, as shown in Table 7.

Table 7. Challenges of using a differentiated instruction strategy by axis

\begin{tabular}{llll}
\hline Axis & Average & Standard Deviation & Order \\
\hline Challenges related to the school environment. & 3.59 & 1.113 & 2 \\
Challenges related to teachers. & 3.28 & 1.174 & 4 \\
Challenges related to students. & 3.62 & 0.971 & 1 \\
Challenges related to school courses. & 3.16 & 1.191 & 5 \\
Challenges related to the nature of the differentiated instruction strategy. & 3.56 & 1.012 & 3 \\
\hline
\end{tabular}

The data in Table 7 shows that according to the respondents the greatest challenges to the implementation of the differentiated instruction strategy are those related to students, which have an arithmetic mean of 3.62. This is followed by challenges related to the school environment, with an arithmetic mean of 3.59 , then the challenges related to the nature of the differentiated instruction strategy (arithmetic mean, 3.56), followed by the teacher-related challenges (3.28). The least of the challenges according to the respondents related to school courses with an arithmetic mean of 3.16 .

The overall result of the challenges was medium, with an arithmetic mean of the total of challenges of 3.44. Thus, this result is similar in terms of results to other studies, including Al-Rawadiyya (2001), Al-Humizi (2007) and Al-Salim (2012). 
The researcher believes that this result may be due to the similarity of the central education system in general, starting from the school environment, through the teachers and students to the courses and the nature of the teaching strategy, being combined in the formation of some of the challenges that hinder the use of modern teaching strategies in the classroom environment.

To answer the sixth study question, "Are there differences in the challenges of using a differentiated instruction strategy according to the educational stage?", the one-way analysis of variance was used to determine differences among variables, as shown in Table 8.

Table 8. Differences in the challenges of using differentiated instruction strategies according to the educational stage

\begin{tabular}{|c|c|c|c|c|c|c|}
\hline Axis & $\begin{array}{c}\text { Source of } \\
\text { Contrast }\end{array}$ & Total of Squares & Squares Mean & $\begin{array}{l}\text { Degree of } \\
\text { freedom }\end{array}$ & $\mathrm{F}$ & Significance \\
\hline \multirow{2}{*}{$\begin{array}{l}\text { Challenges related to } \\
\text { the school } \\
\text { environment }\end{array}$} & $\begin{array}{c}\text { Between } \\
\text { groups }\end{array}$ & 170.140 & 85.070 & 2 & \multirow[b]{2}{*}{1.760} & \multirow[b]{2}{*}{0.174} \\
\hline & $\begin{array}{l}\text { Within } \\
\text { groups }\end{array}$ & 13144.769 & 48.326 & 272 & & \\
\hline \multirow{2}{*}{$\begin{array}{l}\text { Challenges related to } \\
\text { teachers }\end{array}$} & $\begin{array}{c}\text { Between } \\
\text { groups }\end{array}$ & 149.666 & 74.833 & 2 & \multirow{2}{*}{1.733} & \multirow{2}{*}{0.179} \\
\hline & $\begin{array}{l}\text { Within } \\
\text { groups }\end{array}$ & 11743.876 & 43.176 & 272 & & \\
\hline \multirow{2}{*}{$\begin{array}{l}\text { Challenges related to } \\
\text { students }\end{array}$} & $\begin{array}{c}\text { Between } \\
\text { groups }\end{array}$ & 92.863 & 46.431 & 2 & \multirow{2}{*}{1.622} & \multirow{2}{*}{0.199} \\
\hline & $\begin{array}{l}\text { Within } \\
\text { groups }\end{array}$ & 7784.643 & 28.620 & 272 & & \\
\hline \multirow{2}{*}{$\begin{array}{l}\text { Challenges related to } \\
\text { courses }\end{array}$} & $\begin{array}{l}\text { Between } \\
\text { groups }\end{array}$ & 39.715 & 19.858 & 2 & \multirow{2}{*}{0.633} & \multirow{2}{*}{0.532} \\
\hline & $\begin{array}{l}\text { Within } \\
\text { groups }\end{array}$ & 8526.830 & 31.349 & 272 & & \\
\hline \multirow{2}{*}{$\begin{array}{l}\text { Challenges related to } \\
\text { the nature of the } \\
\text { differentiated } \\
\text { instruction strategy }\end{array}$} & $\begin{array}{c}\text { Between } \\
\text { groups }\end{array}$ & 83.929 & 41.964 & 2 & \multirow{2}{*}{1.318} & \multirow{2}{*}{0.269} \\
\hline & $\begin{array}{l}\text { Within } \\
\text { groups }\end{array}$ & 8659.948 & 31.838 & 272 & & \\
\hline
\end{tabular}

It is clear from the date in Table 8 that there are no statistically significant differences in the challenges of using the differentiated instruction strategy according to the educational stage in the axes. This is consistent with the study of Al-Hamizi (2007). The researcher attributes this to the challenges faced by male and female teachers in various educational stages being similar. This due to the similarity of the educational and administrative policies followed by the Ministry of Education in the Kingdom of Saudi Arabia, whether at the primary, intermediate or secondary levels.

To answer the seventh question of the study, "Are there differences in the challenges of using differentiated instruction strategy according to gender (male and female)?" the t-test was calculated to indicate differences between the two groups, as show in Table 9 .

Table 9. Differences in the challenges of using differentiated instruction strategy according to gender

\begin{tabular}{|c|c|c|c|c|c|}
\hline Challenges & Gender & $\begin{array}{c}\text { Standard } \\
\text { Deviation }\end{array}$ & Mean & T-test & Significance \\
\hline \multirow{2}{*}{ Challenges related to the school environment } & Males & 6.07958 & 51.6842 & \multirow{2}{*}{1.260} & \multirow{2}{*}{0.040} \\
\hline & Females & 7.51757 & 50.4846 & & \\
\hline \multirow{2}{*}{ Challenges related to teachers } & Males & 5.61694 & 41.1579 & \multirow{2}{*}{4.677} & \multirow{2}{*}{0.011} \\
\hline & Females & 6.84625 & 37.6335 & & \\
\hline \multirow{2}{*}{ Challenges related to students } & Males & 4.69766 & 29.0526 & \multirow{2}{*}{2.552} & \multirow{2}{*}{0.011} \\
\hline & Females & 5.70734 & 27.4472 & & \\
\hline Challenges related to courses & Males & 4.70226 & 27.0614 & 1.723 & 0.036 \\
\hline
\end{tabular}




\begin{tabular}{lcccc}
\hline & Females & 6.10483 & 25.8075 \\
& Males & 4.82941 & 36.2193 & 2.004 \\
Challenges related to the nature of the differentiated instruction strategy & 0.046 & 6.11923 & 34.8944 \\
\hline
\end{tabular}

It is clear from the data in Table 9 that there are statistically significant differences between the genders in all the challenges at the level of significance 0.05 in favour of males compared to females. This result differs from that of Rawadiyah (2001) but is similar to the results of Rubaie (2015). The researcher attributes this result to the difference in abilities and motivation of male teachers from female teachers, which contributed to their willingness to adapt to the modern teaching strategies and use them in classrooms more effectively than their female counterparts.

\section{Conclusions}

- The overall degree of challenges of using the differentiated instruction strategy was found to be medium.

- The main challenges highlighted by the participants related to the students, but challenges related to the school environment and nature of the differentiated instruction strategy had almost similar scores.

- However, the challenges related to teachers and school courses were considered less problematical.

- The challenges with the highest average were density of students per classroom (4.52), failure to prepare the teacher before service in a way that suits the requirements of differentiated instruction (4.11), lack of availability of educational equipment and Instruments to apply the differentiated instruction strategy (4.05), weakness of students' conviction in using the differentiated instruction strategy (4.03), and students are used to traditional teaching strategies (4.01).

- The challenges with the lowest average were the teacher fears that the school administration will not accept the use of a differentiated instruction strategy with the students (2.35), and concentration of courses on cognitive aspects, prompting and memorization (2.49).

- There are no statistically significant differences in the challenges of using the differentiated instruction strategy according to the educational stage in the axes.

- There are statistically significant differences between the genders in all the challenges at the level of significance 0.05 in favour of males compared to females.

- The importance of differentiated instruction strategy in the classroom environment is confirmed, which supports theoretical literature.

\section{Recommendations and Suggestions}

- Holding workshops and training courses for teachers on how to implement the differentiated instruction strategy, and provide them with practical models for the application of this strategy in school courses.

- Providing all means of support to encourage male and female teachers working in the field of education to use modern teaching strategies, especially the differentiated instruction strategy.

- Educating principals and public education supervisors to the necessity of encouraging teachers to use modern teaching strategies in classrooms.

- Conducting further studies on differentiated instruction and its application in higher education in the Kingdom of Saudi Arabia.

\section{References}

Al Magraby, S. (2011). The Effectiveness of an electronic program based on the differentiated instruction strategy in the development of conceptual comprehension in the Hadith subject among the sixth grade students in Riyadh city (Unpublished master's thesis). Imam Muhammad bin Saud Islamic University, Kingdom of Saudi Arabia.

Al Raee, A. (2014). The effectiveness of the differentiated instruction strategy in the teaching of mathematics on the acquisition of mathematical concepts and inclination to mathematics of seventh grade fundamental students in Gaza (Unpublished master's thesis). Islamic University, Palestine.

Al Roadia, S. (2001). Obstacles to the use of modern methods for teaching social studies subjects in fundamental education in Jordan. Journal of Educational Research Center, Qatar University, 24, 101-137.

Al Shokirat, M. (2009). Teaching and Evaluation Strategies, Articles in the Development of Education (print 1). 
Dar Al-Furqan, Amman, Jordan.

Al Slim, G. (2012). Obstacles of the use of differentiated instruction strategy in the teaching of Islamic courses in the primary stage from the point of view of female teachers in Riyadh City. Journal of Education, Al-Azhar University, 3(151), 379-419.

Al-Rashidi, K. (2015). The effectiveness of differentiated instruction in Improving the Level of motivation towards science learning among deaf students in the primary stage. Journal of Education, Al-Azhar University, 1(163), 1-52.

Al-Rubaie, A. (2015). The extent to which the teachers of Islamic education of high fundamental level have the teaching skills of differentiated instruction, in the Southern Mazar district from their own point of view (Master's thesis, Mutah University, Jordan).

Atia, M. (2009). Modern Strategies and Methods of Teaching (Print 1). Dar Al-Manahg for Publishing and Distribution, Amman, Jordan.

Bantis, M. (2008). Using Task Based Instruction to Provide Differentiated Instruction for English Language Learners (Unpublished master's thesis). University of South California.

Campbell, B. (2008). Handbook of differentiated instruction using the multiple intelligences lesson plans and more. Boston, Pearson Education Inc.

Ellis, D. et al. (2007). Improving Mathematics Skills Using Differentiated Instruction with Primary and High School Students. An Action Research Project Submitted to the Graduate Faculty of the Degree of Master of Arts in Teaching and Leadership. Chicago.

Good, M. (2006). Differentiated Instruction: Principles and Teaching for the Elementary Grades. San Rafael, CA, School of Business, Education, and Leadership at Dominican University of California.

Hamizi, A. (2007). Difficulties facing intermediate schoolteachers in Jazan Educational City when using modern teaching strategies (Master's thesis, King Saud University, Riyadh).

Helaisi, M. (2011). The Effect of using differentiated instruction on achievement in English Language Course for Sixth Grade Students (Master's thesis, Umm Al-Qura University, the Kingdom of Saudi Arabia).

Hobson, M. (2008). An Analysis of Differentiated Strategies used by Middle School Teachers in Heterogeneously Grouped Classrooms (Unpublished master's thesis, University of North Carolina Wilmington).

Koeze, P. (2007). Differentiated instruction: The effect on student achievement in an elementary school (Published thesis EdD, Eastern Michigan).

Kogec, K. et al. (2008). Teacher's guide for improving teaching and learning methods in Arab World schools (Diversification of Teaching), UNESCO Regional Office in the Arab States, Beirut, Lebanon.

Lakani, A., \& Al Jamal, A. (2003). Glossary of Educational Terms, Knowledge in Curriculum and Teaching Methods. World of Books, Cairo, Egypt.

Obeedat, Z., \& Abu-Al Semaid, S. (2009). Teaching Strategies in the 21st Century, Teacher's and Educational Supervisor's Guide (Print 2). Dar Dibuno for Publishing and Distribution, Amman, Jordan.

Tomlinson, C. (2008). The Goals of Differentiation. Education Leadership, 66(3), 26-30.

Ziebell, J. (2002). Differentiated Instruction. Levine, USA.

\section{Copyrights}

Copyright for this article is retained by the author(s), with first publication rights granted to the journal.

This is an open-access article distributed under the terms and conditions of the Creative Commons Attribution license (http://creativecommons.org/licenses/by/4.0/). 